This item was submitted to Loughborough's Research Repository by the author.

Items in Figshare are protected by copyright, with all rights reserved, unless otherwise indicated.

Incorporating subjective end-user perceptions in the design process: a study of leg guard comfort in cricket

PLEASE CITE THE PUBLISHED VERSION

http://dx.doi.org/10.1243/17543371JSET31

PUBLISHER

Professional Engineering Publishing (@ IMechE)

VERSION

AM (Accepted Manuscript)

LICENCE

CC BY-NC-ND 4.0

REPOSITORY RECORD

Webster, James, and Jonathan R. Roberts. 2019. "Incorporating Subjective End-user Perceptions in the Design Process: A Study of Leg Guard Comfort in Cricket”. figshare. https://hdl.handle.net/2134/10855. 
This item was submitted to Loughborough's Institutional Repository (https://dspace.lboro.ac.uk/) by the author and is made available under the following Creative Commons Licence conditions.

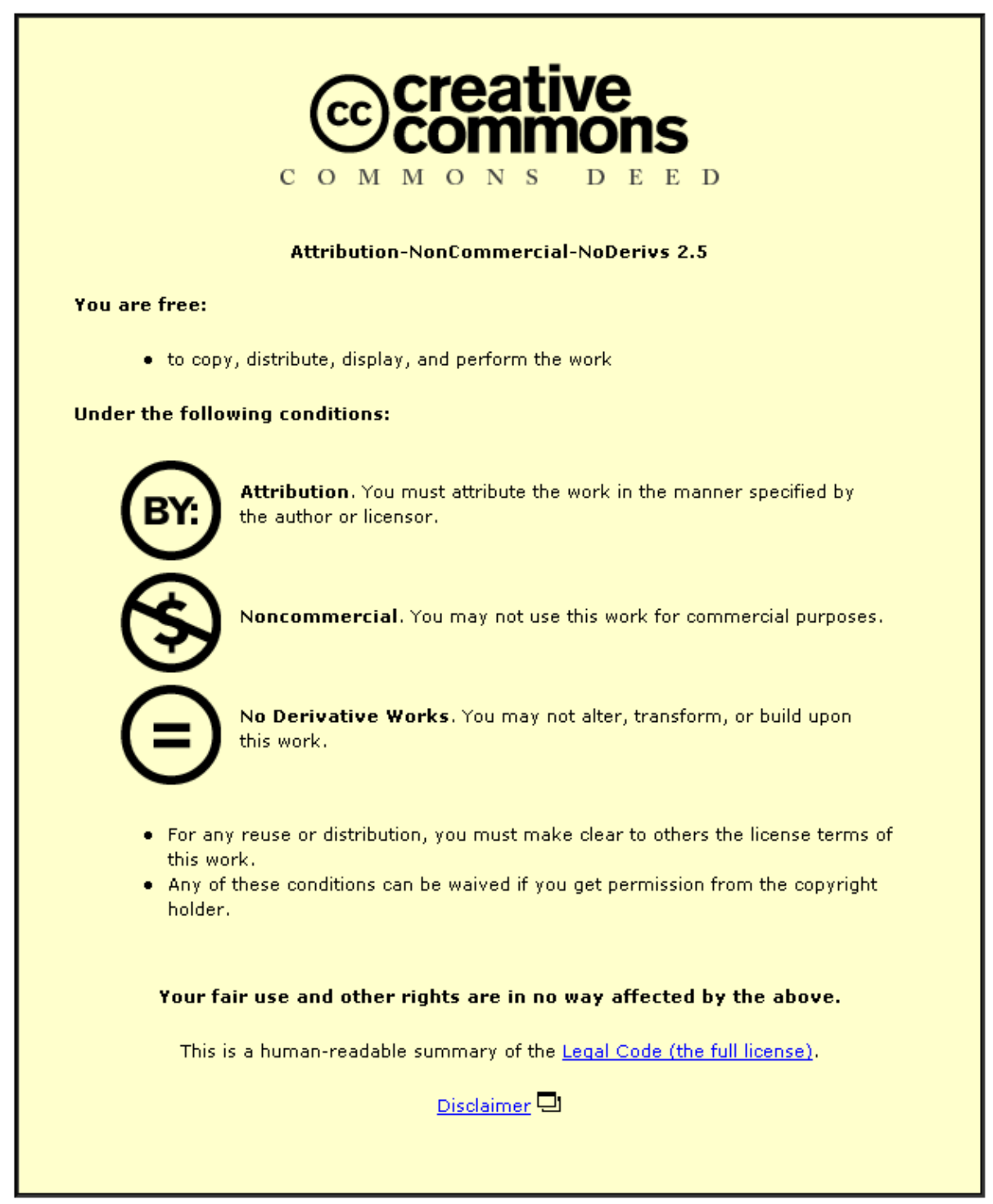

For the full text of this licence, please go to: http://creativecommons.org/licenses/by-nc-nd/2.5/ 


\title{
Incorporating subjective end-user perceptions in the design process: a study of leg guard comfort in cricket
}

J M Webster* and J Roberts

Sports Technology Research Group, Loughborough University, Loughborough, UK

The manuscript was received on 25 September 2008 and was accepted after revision for publication on 4 December 2008.

DOI: 10.1243/17543371JSET31

\begin{abstract}
During the design of sports equipment, the main focus is usually on physical performance attributes, neglecting key subjective factors such as feel or comfort. The personal protective equipment worn in sport is a typical example of where injury prevention has taken precedence over user comfort, but it is anticipated that, with an improved approach to the design process, comfort can be enhanced without sacrificing protection. Using cricket leg guards as an example, this study aims to develop a systematic method for assessing user perceptions and incorporating them into the design process. Using this method, players' perceptions of the factors that influence comfort were elicited through the use of co-discovery sessions, focus groups, and individual interviews and analysed through an inductive process to produce a comfort model. The relative importance of the different comfort dimensions were identified through the use of an online questionnaire utilizing the analytical hierarchy process method. Through the combination of these methods, six general dimensions were identified with a weighting regarding the amount to which each one determines a user's perceived comfort. These results demonstrate how subjective analysis can be integrated into the design process, allowing for end users' preferences to be considered and integrated.
\end{abstract}

Keywords: cricket, protective equipment, subjective analysis

\section{INTRODUCTION}

Because of the increasingly competitive nature of the sports equipment and apparel market manufacturers are constantly trying to improve the performance and comfort of athletes through the development of new products. To date, the majority of research has focused on increasing performance through enhanced power, speed, or accuracy, with less emphasis placed on evaluating perceptions of comfort, even though the user's subjective assessment ultimately determines their satisfaction with a product and their perception of the brand. Customer satisfaction is a phenomenon that typically occurs when the perceived performance and benefits of a product exceed the expectations of the customer $[\mathbf{1}]$ and it is widely accepted that customer satisfaction levels and long-term brand loyalty are

*Corresponding author: Sports Technology Research Group, Wolfson School of Mechanical and Manufacturing Engineering, Loughborough University, Loughborough, Leicestershire, LE11 3TU, UK.

email: j.m.f.webster@lboro.ac.uk influenced by emotions during and after the use of a product [2]. Comfort has been identified as having a major influence on these emotions as it is influenced by the state of mind that the individual is in [3] and therefore is an important factor that influences user satisfaction with a product.

For sports such as cricket, which require large amounts of personal protective equipment (PPE), comfort is of increased importance owing to the interactivity between player and equipment. Historically, comfort was considered a luxury and of secondary importance to other features such as protection within PPE. The death of seven collegiate American footballers due to heat stroke between 1959 and 1962 [4] demonstrated that comfort was not just a luxury but a key safety feature, which needs to be considered when developing sports equipment. Comfort has also been found to influence performance across a wide range of both cognitive, and physical activities, highlighting the negative effects that discomfort can have on students' examination performance and maximal grip strength performance 
[5-8], again demonstrating the need for products to be developed with increased perceived comfort.

Initially, research within the field of comfort was plagued with idiosyncratic terminology that was ill defined [9], causing a lack of operational constructs and a general confusion about attributes relevant to comfort and the qualities that are important [10]. As research progressed, a general comfort framework was developed [11] and modified [12, 13] finally resulting in the 'comfort model' described by Branson and Sweeney [14]. The Branson-Sweeney [14] model maintained the idea developed by Fourt and Hollies [11] that comfort is determined by the interaction of the individual with their clothing in a particular environment, which has become known as the comfort triad. In their model, however, Branson and Sweeney [14] shifted the focus away from this being the main categorization mechanism, stating that each component in the comfort triad consists of both physical and social-psychological dimensions. For example, physical dimensions of clothing include fibre content, fabric structure, and heat transfer properties, whereas the social-psychological attributes include style and fashionability. The physical factors are often referred to as variables because most physical attributes are readily capable of being controlled or manipulated to produce observable changes in physiological systems, whereas the socialpsychological dimensions are documented as being much more fuzzy and difficult to quantify but are growing in recognition regarding their influence on perceived comfort [14].

Through the use of this model, further research has identified four main clothing and equipment aspects which influence perceived comfort [15-18]:
(a) thermal comfort;
(b) sensorial comfort;
(c) fit;
(d) aesthetics.

Each aspect was seen to be made up of different clothing properties; for example, abrasiveness, softness, and coarseness were seen to determine sensorial comfort, whereas thermal comfort consisted of absorbency and breathability [17]. Although this generalized comfort model did further develop the understanding of how perceptions of comfort are generated, the appropriateness of one model for all sporting situations and items of clothing has yet to be justified, owing to the inherent differences between sports and the nature in which the equipment and clothing is used. Within the Branson-Sweeney [14] model, they indicate the interactive nature of the different elements contributing to the user's perceived comfort. There is no indication, however, of the amount that different factors contribute to the overall perceived comfort and whether this is dependent on the individual and the nature of use. For example, cricket pads are worn over the top of trousers which will affect the characteristics that are most influential to the user's perceived comfort, compared with an item of PPE which directly contacts the skin.

Current work within the field of comfort has largely focused on product evaluation rather than consumer needs, through the utilization of questionnaires to obtain subjective ratings. This focus has been evident within a range of studies looking at military and services PPE [15] and school backpacks [19]. Although this research is invaluable in terms of product assessment, its appropriateness for consumer needs analysis is questionable because of the lack of opportunity for the participant to describe fully the sensation of discomfort and its cause.

In the wider field of product development, numerous approaches have been advocated for incorporating the 'voice of the consumer' (VOC) into the design process, such as quality function deployment (QFD) and Kansei engineering. Ulrich and Eppinger [20] discussed the methodological requirements for identifying customer needs and proposed the following aims for a successful method:

(a) to ensure that the product is focused on customer needs;

(b) to identify latent or hidden needs as well as explicit needs;

(c) to provide a fact base to justify product specifications;

(d) to create an archival record of the needs activity of the development process;

(e) to ensure that no critical customer need is missed or forgotten;

(f) to develop a common understanding of customer needs among members of the development team.

Through the adoption of these methodological considerations it is possible for a channel of information between the target consumer and product developers to be established, allowing interaction between them to aid in the development of a more suitable product.

Several methods have been used within product development to help bridge this gap between the end user and the design team. Kansei engineering involves the identification of product features that influence consumer satisfaction through the use of product semantics, i.e. words or expressions describing product attributes that are collected from interviews, articles, web pages, advertisements, etc. [21]. Underlying patterns in the semantic space can then be obtained by analysing subjects' product ratings obtained from semantic difference scales formed from the identified words [22]. Although this process highlights product attributes that influence consumer perception, little detailed information on 
the individual attributes is obtained and limited understanding is derived regarding complex consumer needs. The aim of QFD is to deploy the VOC throughout the design process by relating product features to consumer needs [23]. QFD is more of a development tool that builds on consumer needs that have to be identified in advance. Many different techniques have been used to identify these needs including interviews, focus groups, and repertory grids. These in-depth approaches are more suitable for understanding the comfort of a product as they are likely to provide much more detailed information on product attributes such as their physical and social-psychological influence on users' comfort [24].

Therefore, a more in-depth user-driven approach is required if the design process is to address the end users' needs in terms of comfort, developing an understanding of key design features and the way that they interact to determine perceived comfort.

This study aims to develop a systematic method for identifying and understanding the complex interaction and relative importance of the factors that influence comfort, through the development of a specific comfort model. This information can then be utilized within the design process, and differences between groups of players can be studied. Through the completion of these aims, this study hopes to build on previous work by Barrass et al. [23], by developing players' perceptions into a hierarchical structure providing design teams with greater amounts of information from the end user, allowing for more comfortable products to be designed and manufactured.

\section{DEVELOPMENT OF A COMFORT MODEL FOR CRICKET LEG GUARDS}

Previous research has utilized an inductive analysis process to represent players' perceptions on a variety of subjects and items of sporting equipment [23, 25-29]. The inductive analysis process structures raw qualitative data, collected through techniques such as interviews, allowing significant components to emerge from the data through the process of clustering. This method of data analysis can be used in conjunction with a process known as structured relationship modelling, developed by Roberts et al. [29], which allows any inter-component links to be identified, giving a greater understanding of how different design features interact and contribute to users' perceptions. This method was deemed suitable for developing an appropriate comfort model owing to the increased receptiveness and input of consumer information and the reduced constraints of data collection.

To develop a comfort model, a two-stage methodology was developed. The first stage aimed to generate a representative tree structure and relationship model of factors affecting perceived comfort, whereas the second phase looked to develop this tree structure into a hierarchy, indicating the relative importance of the different factors. The development of a hierarchy is discussed in section 3 .

The first phase was conducted to allow design features perceived to influence comfort to be identified through the technique of structured relationship modelling developed by Roberts et al. [29]. Thistechnique was chosen for the following reasons [30].

1. Subjects can be observed using the product in question.

2. It provides an opportunity for subjects to experience and discuss the beneficial and detrimental features of the product.

3. The user is able to discuss possible improvements in the design.

4. The process is flexible and consumer led, focusing on issues of importance to them.

5. It allows the use of visual and tactile stimuli to increase the quantity and quality of data produced.

6. The investigator can probe answers given by the subject, increasing understanding.

7. Non-verbal communication can be recorded.

\subsection{Methodology}

The study design process developed by Roberts et al. [29] was used as a basis to generate the experimental design but was modified to include methodological triangulation in the data collection process. Methodological triangulation was used in recognition of potential effects of biases when only one method is used [31]. To increase the validity and reliability of results, three data collection methods were utilized; these were co-discovery, focus groups, and individual interviews. These three methods were used because their individual strengths appropriately balance out

Table 1 Characteristics of three data collection methods

\begin{tabular}{llll}
\hline & Co-discovery & Focus group & Individual interviews \\
\hline Opportunities for probing & None & Extensive & Extensive \\
Investigator influence & Limited & Extensive & Extensive \\
Group effect & Extensive & Extensive & None \\
Freedom of participant & Extensive & Average & Limited \\
\hline
\end{tabular}


each other's weaknesses, as demonstrated in Table 1. The main possible sources of error were identified as investigator bias and group effect. To compensate for these, a co-discovery session was included in order to provide a source of data collection where the interviewer was not present, preventing them from being able to influence the data through predetermined theories, beliefs, or opinions. The individual interviews were also included to compensate for existing roles within the group influencing the results. This trio of methods was considered more suitable than the repertory grid technique as, in a study comparing three attribute elicitation procedures, Steenkamp and Van Trijp [32] concluded that free elicitation (i.e. interviews) yielded more attributes articulated at a higher level, was preferred by the subject, and was more time efficient when compared with repertory grids.

\subsubsection{Participants}

In accordance with the work of Patton [33], purposeful sampling was used to increase comprehensiveness of results through the utilization of 'informationrich' participants, allowing for greater insight into issues of central importance. For the first phase of this study, 20 participants playing at either county first- or second-team level, or an equivalent standard, were used owing to the increased amount of time spent using the equipment in training and competition. The participants had a mean age of $19.9( \pm 1.7)$ years, were male, and all played as top-order batsman. Sixteen of the participants participated in the co-discovery and focus group sessions, and four participated in the individual interview process used for validation purposes.

\subsubsection{Co-discovery}

The test procedure began with a co-discovery session involving a group of five or six players with no investigator present. The players were asked to investigate the six pairs of pads, which were chosen as a representative sample of the market, and to discuss the positive and negative attributes of the pads, and the features that they would change to increase comfort. The co-discovery sessions lasted approximately $20 \mathrm{~min}$ and all data were recorded for further analysis.

\subsubsection{Practical testing}

Following the co-discovery session, each participant was required to use two different types of pad (allocated at random) for 5-10 min, facing a minimum of ten balls in each pad. The players were encouraged to run between the wickets when they felt they had hit a scoring shot. They were also asked to pad several balls away, allowing for a complete assessment of the pads' performance. No control pads were used to reduce kinaesthetic after-effects, preventing fixations on certain stimuli and augmentation or reduction in sensations [34]. Once each player had completed the practical testing, they were interviewed within a focus group setting.

\subsubsection{Focus group}

For the focus groups, a naturalistic approach was used, because this research was of an explorative nature. Naturalistic inquiry is deemed suitable as theory is of an a posteriori rather than a priori nature. This is seen to be beneficial in exploratory research [35] because it minimizes investigator bias and restraint on subjects' responses, allowing for a more detailed and representative reflection of subjects' perceptions. A framework for the focus group session was developed in the form of an interview guide, where a list of possible questions was outlined. Each question was carefully worded to prevent them from being directive or suggestive, to allow a true reflection of the subjects' opinions to be gathered. Although some questions were set, the direction of the discussion was determined by the participants responses. Open-ended questions were used because of the greater understanding gained through them [36], allowing the researcher to gain a more insightful reflection of the participants' perceptions, while capturing their view point without predetermined biases influencing the results [37].

\subsection{Data analysis procedure}

An inductive analysis was conducted to analyse the initial data. This method was considered the most suitable qualitative data analysis technique as it condenses extensive and varied raw text data into a brief summary format, establishing clear links between the research objectives and the summary findings. Finally it allows for models and theories to be developed about the underlying structure of experiences or processes which are evident in the raw data [37].

An inductive analysis is considered beneficial for discovery research as it allows findings to emerge from the frequent, dominant, or significant themes inherent in the raw data [37], rather than using previous findings to determine the structure of the results, as can be seen in deductive methods. This approach has been utilized in several well-established methods including 'grounded theory' [38], where it is used to aid understanding and to give meaning to complex data through grouping together of themes and subcategories present within the raw data.

The first stage in the analysis procedure was to transcribe verbatim the recorded sessions and to become familiar with the content. Once familiarity with the data was gained, it was organized into 
structured meaningful themes by comparing and contrasting each quote with all other quotes and emergent themes, so that quotes with a similar meaning could be united and quotes with different meanings separated. This process was conducted using the software package NVIVO 7, which assists in grouping together similar quotes, allowing different categories to be formed and linked together to produce base themes. The base themes were then grouped together to form lower-order subthemes. Within this process, alternative classification schemes of the same base themes were created; all possible classifications were formed and refined by removing redundant classifications. A classification was considered to be redundant if all base themes could be recoded into another alternative dimension [29]. This process was then repeated until it was not possible to group further the different categories together. The results were validated through investigator triangulation to ensure the correct grouping of quotes and base themes, reducing possible bias and increasing validity.

\subsection{Validation process}

Four individual interviews were then conducted to validate the results further. The interviews were conducted while participants completed a practical test of different pads, in a similar manner to the practical assessment previously described. Four different pads were used by each participant, covering the range of pads available on the market. Prior to the testing of each pad, the participants were asked for their initial assessment of the equipment. Throughout the use of each pad, feedback on its performance was recorded and a final evaluation was gathered post-use. This method was then repeated for all pads. The data collected were transcribed and analysed through a deductive process, where quotes were grouped into the themes that emerged from the inductive analysis of the focus group and co-discovery sessions. By utilizing a deductive approach, the applicability of the model developed through the inductive analysis process previously outlined was assessed. If no new themes emerged, it could be concluded that a data saturation point had been reached.

\subsection{Structured relationship modelling}

The data collected were then analysed through the use of a technique called structured relationship modelling, developed by Roberts et al. [29]. Quotes highlighting the interaction of different factors influencing the users' perceived comfort were used to link different themes, and dimensions allowing for further understanding of how different aspects of the pad design interact to determine perceived comfort.

\subsection{Tree structure results}

Six general dimensions emerged from the inductive analysis of the data. These were 'fit', 'aesthetics', 'weight', 'protection', 'thermal comfort', and 'sensorial comfort'. As the complete set of results is too extensive for the confines of this paper, the example of aesthetics will be presented to illustrate the results. The general dimension of aesthetics, depicted in Fig. 1, demonstrates how the data were processed, progressing from initial quotes on the left to the general dimension on the right, through the use of the technique known as clustering [29].

The aesthetics dimension (Fig. 1) was built from the three subthemes of 'look of the pad', 'self-image' and 'shape'. A player's initial impressions of a pad are largely determined by the appearance and this can influence their preferences.

'They could be the best pad on the table, but I would sooner go for the better looking pad.'

'[I'd rank] these fourth, just purely because they don't look like a cricket pad.'

The appearance of a pad was found to influence comfort in a psychological manner owing to the stereotypes and traditions of the sport. This was encompassed by the base theme 'style of the pad', and generally players described a preference for a more traditional-looking pad.

'More traditional [design] than futuristic, that's the way I like pads.'

'These rank lower because of looks. They are a good pad. . .they are light, but the looks for me [aren't right]; they just don't look like a cricket pad.'

'I like the idea of these and they are a good pad but again, personal preference, I like the old school-looking pads which a lot of players do, the traditional type.'

Although these examples show that the majority of players prefer a traditional-looking pad there is also the suggestion that, as technology becomes increasingly important, change is imminent and, over time, objections to the look of modern pads will be overcome.

“ "Does it look good?" will die out when people realize that, to increase performance, you have to go with modern-looking pads.'

'In the end, futuristic pads will become more popular .. but, at the moment, people want to stick to what they are used to.'

'Because of how light they are and how well they hug your leg and how good they feel when you are running ... you will have to compromise [on looks] a bit I suppose.' 


\section{Quotes \\ Low order \\ sub- \\ themes}
High order
sub-
themes

General

Dimension

"You know by the make they will look good"

"You go with the make you are used to as you like their pads design"

\section{Brand image}

"The colour on the back isn't that nice"

Colour

"They just look horrible"

"I don't really like the look of them"

"They don't look good. The opposite to everything we want"

"They look pretty good"

"They are really nice look great"

"Looks wise they look good"

"The knee roll looks a bit too much"

"Comfy and light but too much knee roll"

"Yeah I don't like the look of the skinny knee roll"

Look of the knee roll

"I like traditional looking pads"

"There is a certain balance between futuristic and old fashioned"

"It looks like a pad, traditional"

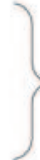

Dislike the look

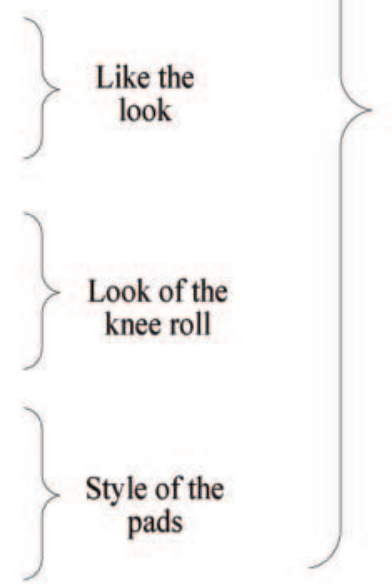

Look of the pad

"If you went out wearing them you would just want to come straight back in"

"People get abused if they come out in really big pads"

"You would get absolutely ripped for them, look at them"

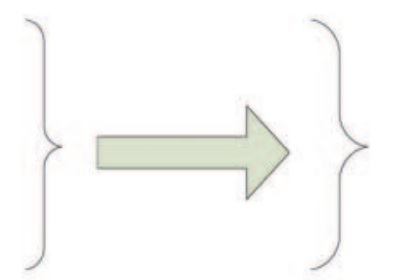

\section{Self}

Aesthetics

\section{"I like them until the knee"}

"If these just had a nicer finish up here they would be good"

"The top bit is a bit, a bit different and weird"

"The top part is nicely curved"

"The top bit looks much better on these"

"They are thin at the bottom, so I didn't really like them"

"These are narrow at the bottom"

"They need more shape so they look better"

"They are very straight"

"The straight design means they don't have any shape to them"

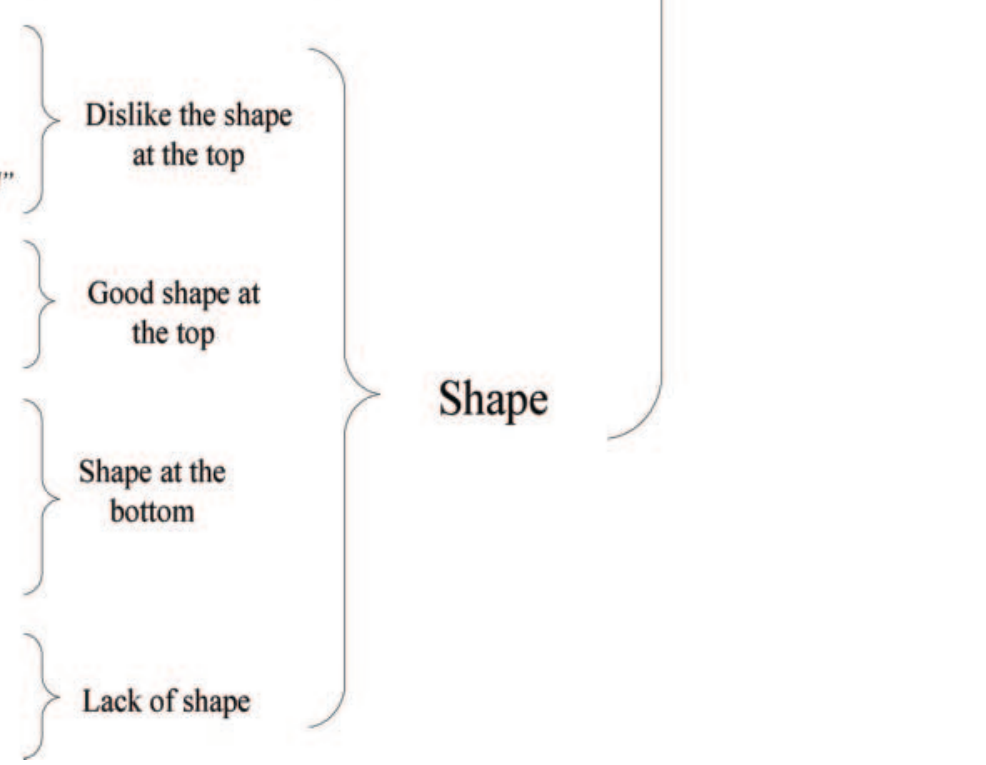

Fig. 1 General dimension tree structure for aesthetics 
These more positive comments suggest that modern designs will become more popular, but it will be a gradual change. Currently, for a pad to be deemed acceptable, a balance between technological advancement and traditional appearance needs to be maintained.

The appearance of a pad can determine a cricketer's willingness to use the pad and can influence how comfortable they will feel. Owing to peer pressure, pad appearance can affect self-consciousness and consequently the user's comfort. Therefore 'selfimage' is the final subtheme of aesthetics.

'They are quite comfortable, though you just look like you have fat legs in them.'

'You would get absolutely ripped for them as look at them; I definitely wouldn't wear these at club level.'

'If you turn up on a Saturday wearing them you would just get annihilated; it wouldn't be worth it, which is probably why most of the county players haven't taken this style of pads on.'

\subsection{Relationship modelling}

A section of the structured relationship model that was developed from the initial map is shown in Fig. 2 and illustrates how different dimensions are perceived to interact. The full relationship model contains all six general dimensions with 13 interdimension relationships.

In Fig. 2, the interaction between the general dimensions of fit and protection can be seen. These interactions highlight the influence that one general dimension can have on another. For example, responses from the participants illustrated the way that the amount that the pad wraps around your leg can influence the users' perceived exposure to the ball, or the amount of padding can determine the perceived flexibility and size of the pad, as well as how the pad affects movement. These relationships were demonstrated through various quotes about shape to the body and exposure to the ball.

'This pad just doesn't shape to the leg; so you feel that the ball can hit you here.'

\section{About amount of padding and movement:}

'These pads have more padding, [but it] makes you feel like you can't move in them.'

About amount of padding and flexibility:

'You want to have extra padding but this makes it less flexible.'

And about amount of padding and size

'This pad has loads of padding which is good, but they feel really big because of it.'
These relationships highlight the interaction between the different dimensions associated with comfort; however, to utilize these results fully in determining possible trade-offs within the design process, further understanding of the contributory affect of each dimension on perceived comfort is still needed.

\section{DEVELOPING A HIERARCHY}

The aim of developing the results from the relationship modelling process into a hierarchy is to allow designers to gain further understanding of product needs, by attributing a relative importance weighting to each of the six general dimensions identified, allowing for trade-offs to be made within the design process to maximize perceived comfort.

Once the initial data had been collected and analysed using the inductive analysis process, the general dimensions identified were utilized within a pair-wise comparison administered to 108 participants through an online questionnaire. The pairwise comparisons were completed in accordance with the analytical hierarchy process (AHP) [39], allowing for the results from the initial data collection and analysis process to be represented in a hierarchical structure. The AHP method was utilized because of its ability to decompose a complex multi-criteria problem into a hierarchy [39] with the advantage of allowing participants to assign different magnitudes of opinion in comparison with the restricted responses within traditional pairwise comparisons. The participants were asked to indicate how much more important one general dimension was compared with another in determining their comfort using a relative importance scale. The scale used to compare fit and weight is illustrated in Fig. 3 as an example.

Using these judgements a prioritized rank order was developed. This was done through the composition of an $n \times n$ pairwise comparison matrix for each respondent according to equation (1)

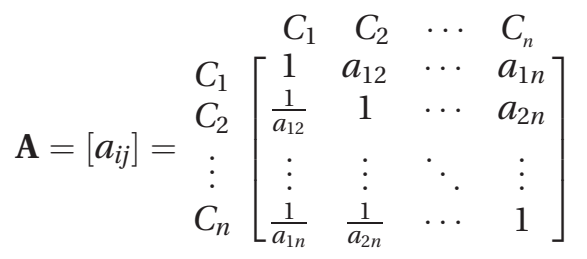

where $n$ is the number of general dimensions. In equation (1), $a_{i j}$ represents a quantified judgement on each pair of elements $C_{i}$ and $C_{j}$ (where $C_{1}, C_{2}, \ldots, C_{n}$ in this case denote the general dimensions). If two elements $C_{i}$ and $C_{j}$ are judged of equal importance, $a_{i j}=a_{j i}=1$. If $C_{i}$ is judged to be 'slightly 


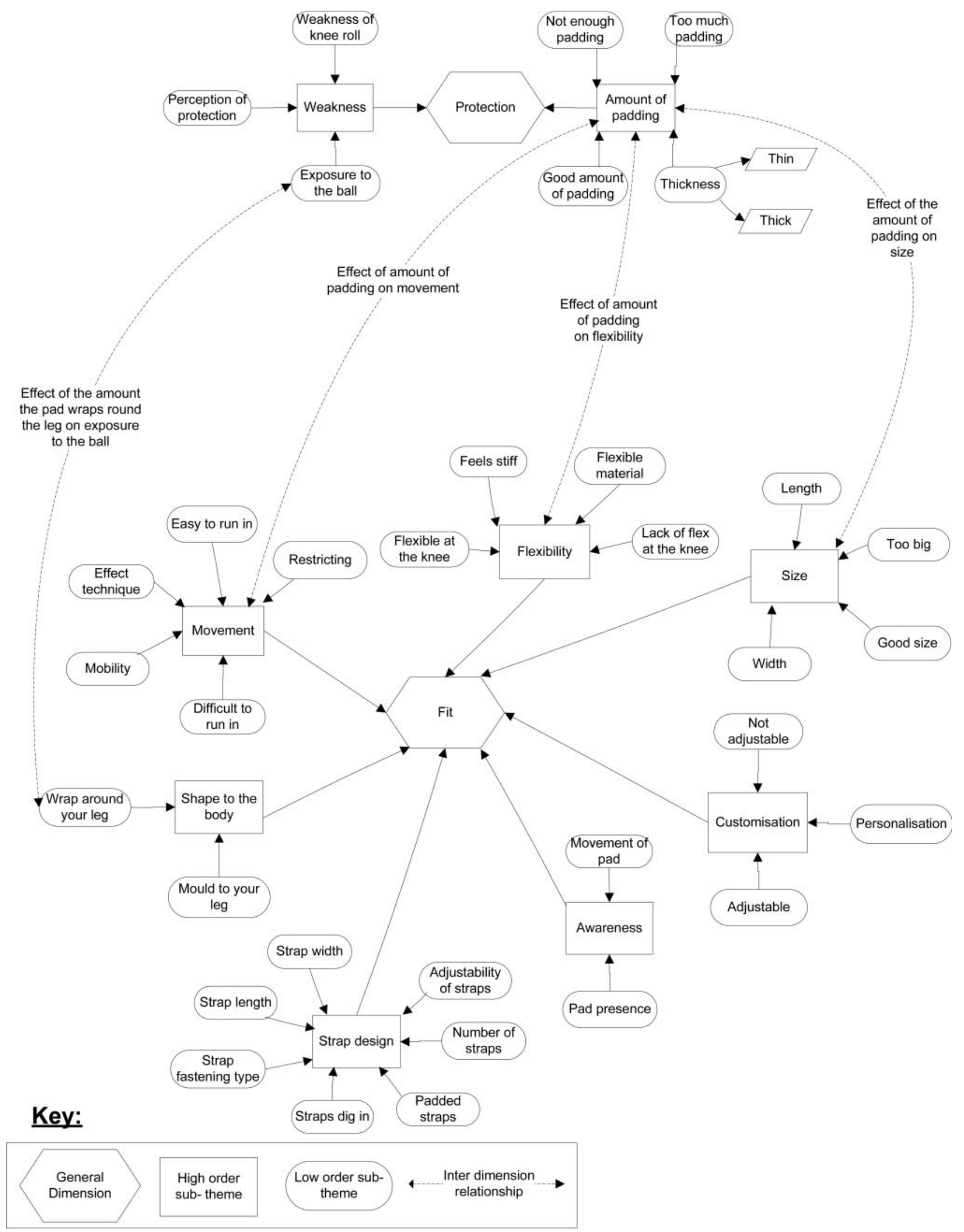

Fig. 2 Example section of the structured relationship model 


\section{Within each of the 5 pairs listed below, move the bars accordingly to show how much more important one factor is than the other.}

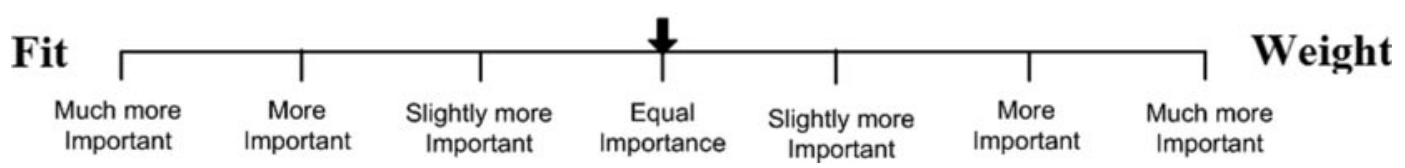

Fig. 3 Example question and response bar used within the AHP online questionnaire

Table 2 Example of a completed pairwise comparison matrix

\begin{tabular}{lllllll}
\hline & Weight & Thermal comfort & Protection & Fit & Sensorial comfort & Aesthetics \\
\hline Weight & 1 & 3 & 3 & 3 & 7 & 7 \\
Thermal comfort & 0.33 & 1 & 0.14 & 0.33 & 3 & 7 \\
Protection & 0.33 & 7 & 1 & 3 & 3 & 7 \\
Fit & 0.33 & 3 & 0.33 & 1 & 3 & 3 \\
Sensorial comfort & 0.14 & 0.33 & 0.33 & 0.33 & 1 & 1 \\
Aesthetics & 0.14 & 0.14 & 0.14 & 0.14 & 0.33 & \\
\hline
\end{tabular}

more important', 'more important', or 'much more important', $a_{i j}$ takes a value of 3,5 , or 7 respectively and $a_{j i}=1 / a_{i j}$. Alternatively if $C_{j}$ is judged to have a greater importance, then $a_{i j}$ takes the value of $\frac{1}{3}$, $\frac{1}{5}$ or $\frac{1}{7}$, depending on the magnitude of importance, and again $a_{j i}=1 / a_{i j}$. An example of a completed matrix is shown in Table 2.

After all pairwise comparison matrices were formed for each respondent, vectors of weights $\boldsymbol{w}$ were computed on the basis of Satty's eigenvector procedure. The weights were calculated through a two-step process; initially the pairwise comparison matrix was normalized through equation (2)

$$
a_{i j}=\frac{a_{i j}}{\sum_{i=1}^{n} a_{i j}}
$$

and then the weights were calculated through equation (3)

$$
w_{i}=\frac{\sum_{j=1}^{n} a_{i j}}{n}
$$

The $\sum_{i=1}^{n} w_{i}=1$, and the values of $w_{i}$ are an indication, in this case, of the relative importance of each comfort dimension for that particular respondent. There is a common relationship between the vector weights $\boldsymbol{w}$ and the pairwise comparison matrix $\mathbf{A}$ demonstrated within equation (4)

$$
\mathbf{A} \boldsymbol{w}=\lambda_{\max } \boldsymbol{w}
$$

Through the use of $\lambda_{\max }$, data can be screened through the development of a consistency ratio (CR) of the estimated vector. The CR can be calculated once the consistency index (CI) for each matrix of order $n$ has been determined through equation (5)

$$
\mathrm{CI}=\frac{\lambda_{\max }-n}{n-1}
$$

Then CR is calculated through equation (6)

$$
\mathrm{CR}=\frac{\mathrm{CI}}{\mathrm{RI}}
$$

$\mathrm{RI}$ is the random consistency index obtained from a randomly generated pairwise comparison matrix and is a set value dependent on $n$, which is the number of general dimensions identified within the first stage of testing. An RI value of 1.24 was used in accordance with the work of Saaty [39]. The CR can vary between 0 and 1 and is a measure of the consistency of an individual subject's responses, with a higher number indicating a greater degree of inconsistency in their data. Typically a maximum value is selected and the data from subjects whose CR exceeds this value are removed from the analysis. For this study, a maximum CR of 0.2 (20 per cent) was utilized instead of 0.1 (10 per cent) to make the results more inclusive and, as a result, the data from eight subjects were removed.

\subsection{Statistical analysis of AHP results}

The weightings determined for each subject were then combined to give an overall weighting. Statistical analysis of the combined AHP results was completed to determine whether there were any significant differences in perceived relative importance of the general dimensions ascertained in the initial analysis. A standard analysis of variance was not suitable because the results were not totally independent of one another; therefore a bootstrapping technique was utilized to obtain a 95 per cent biased corrected accelerated $\left(\mathrm{BC}_{\mathrm{a}}\right)$ confidence interval. This technique involves resampling (with replacement) of a given sample, where subsamples are withdrawn from the original data and replaced by replicating random other 
samples. For example, from the 100 eligible respondents to the questionnaire, a new subsample may consist of 90 of their scores with ten replicated results used to produce a new sample of 100. The mean weighting for this new sample is calculated before the procedure is repeated 10000 times. From this, the 95 per cent $\mathrm{BC}_{\mathrm{a}}$ is calculated.

Utilizing this method allows a valid statistical result even if the standard statistical assumption of normality does not hold. This statistical process was regarded as more valid or reliable than other possible methods such as jackknife and cross-validation as, rather than deleting results, bootstrapping utilizes a constant resampling with replacement method to develop an empirical distribution for a given sample statistic that provides the framework for computing the averages, standard errors, and confidence intervals $[40,41]$. Because the sampling or resampling in the bootstrap method takes place, the combinations of samples are limitless and are driven by random number generators from the Monte Carlo technique. Weightings were deemed significantly different if no overlap occurred between dimensions when the 95 per cent confidence intervals were evaluated.

\subsection{AHP results}

A hierarchy of importance regarding perceived comfort was developed through the use of the AHP, assigning a specific weighting to each of the six general dimensions previously identified. The mean weighting for each dimension for the 100 eligible respondents was calculated and is shown in Fig. 4. Within the 100 accepted responses out of the 108 respondents, the mean inconsistency was 0.126 \pm 0.034 . From the results, it can be seen that fit (30.9 \pm 9.8 per cent) was perceived to be the most important factor affecting comfort, followed by protection (24.2 \pm 9.8 per cent), weight (16.8 \pm 7.2 per cent), thermal comfort (11.97 \pm 6.88 per cent), sensorial comfort (8.32 \pm 5.1 per cent) and then aesthetics (7.78 \pm 5.9 per cent). For a greater understanding of these weightings the statistical method of bootstrapping was utilized, to generate the 95 per cent confidence ranges shown in Table 3. These results indicate a clear difference between all dimensions except for aesthetics and sensorial comfort whose intervals were 6.84-9.20 and 7.49-9.49 respectively, as these are the only two dimensions that overlap.

The data collected within this investigation were also divided into different categories of players, male: female ( $n=72: 28)$ and amateur :professional $(n=66: 34)$ (Fig. 4). When divided into the different categories, a $t$ test indicated no significant differences $(p>0.05)$ between the different groups of players, demonstrating a consistent trend between both sexes and across all levels of performer. Although no significant differences between these categories of players were found, the large standard deviation within the dimensions does suggest some differences of opinion between respondents. To analyse these differences further, the statistical method of clustering was used to analyse whether there are any subgroups within the respondents regarding the relative importance of the different dimensions. Hierarchical clustering was used to study the Euclidean distance to the furthest neighbour. As shown in Fig. 5, the respondents can be split into two distinct groups determined by the perceived importance of protection and fit. Subjects in group 1 placed a higher emphasis on protection $(n=34)$, whereas those in group 2 perceived fit to be of greater importance when determining comfort $(n=56)$. Ten subjects did not fit into either group. It was not possible, however, to identify a demographical characteristic that separated the two groups.

\section{DISCUSSION}

Using cricket leg guards as an example, this study aimed to develop a systematic method, from which an appropriate and specific comfort model could be developed, allowing for more in-depth information to be utilized within the design process. The study also investigated whether different groups of players perceive different design aspects as having a greater influence on comfort.

The inductive analysis and structured relationship modelling process identified the major contributory factors to players' perceived comfort. This information could be utilized in terms of identifying possible trade-offs to be made while designing the leg guard to increase user comfort. To achieve this, further information was required regarding the importance of each factor that contributes to perceived comfort. This information was gathered through the use of the AHP process which produced a hierarchy of the comfort dimensions. These results highlighted perceived fit, protection, and weight as being the most important, while aesthetics and sensorial comfort were identified as the least important factors. Within the focus groups and interviews, however, the appearance of the pads was a major talking point and strong negative feelings were identified with pads which were not of a traditional design.

'I would never wear that pad, just look at it.'

'If I went out in this, I may as well turn round and come back in; I mean you would look ridiculous.'

'These pads are good but they just don't look like a cricket pad; I would like these pads if they were not so out there.' 

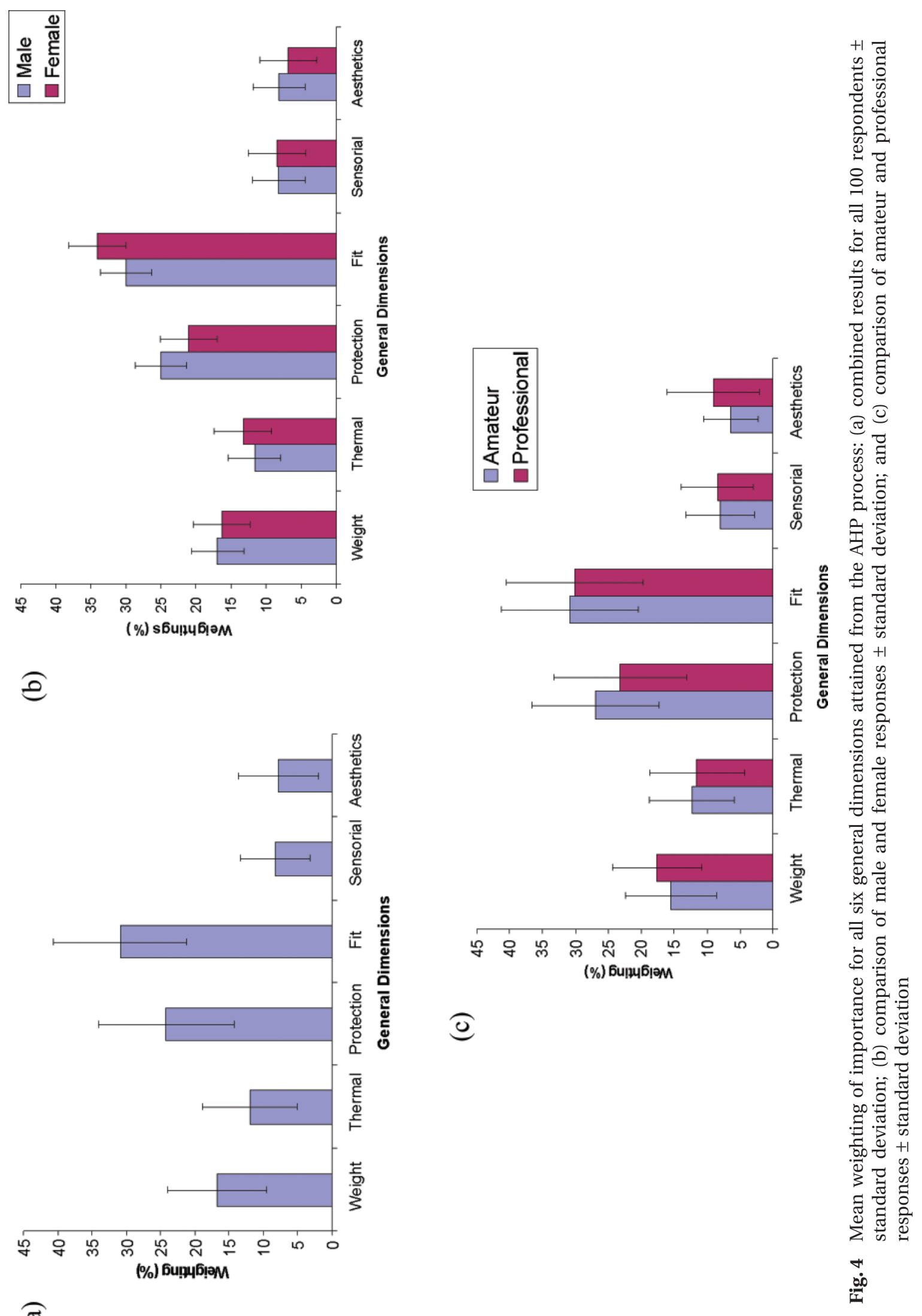

$\overbrace{}^{(0)}$ 
These comments highlight the necessity for a pad to look good and to conform to traditional designs, suggesting that aesthetics are of more importance than emerged from the AHP. This discrepancy demonstrates the benefit of incorporating different processes within the method. Through combining the results, it can be concluded that, as the majority of pads still maintain traditional features, their appearance does not have a large impact on overall comfort. It is only when players are presented with a completely unique modern pad without the traditional features expected that aesthetics begin to have a considerable influence on comfort. These pads, however, are much less common. The initial interview process where pads are presented to the players ascertains their feelings on the full range of pads presented, whereas the questionnaire focuses more on their perceptions of a typical pad, or the pads that

Table 3 Bootstrap 95 per cent confidence intervals for 10000 replicates

\begin{tabular}{lll}
\hline & Lower limit (\%) & Upper limit (\%) \\
\hline Weight & 15.5 & 18.3 \\
Thermal comfort & 10.7 & 13.4 \\
Protection & 22.3 & 26.2 \\
Fit & 29.0 & 32.8 \\
Sensorial comfort & 7.5 & 9.5 \\
Aesthetics & 6.8 & 9.2 \\
\hline
\end{tabular}

they currently use, which for most players will still be a traditional-style pad.

Through the development of this structured relationship model and hierarchy, possible trade-offs can be identified and assessed in accordance with the end users' preferences, improving more influential parameters, while sacrificing parameters perceived to be of lesser significance. The structured relationship model also highlighted inter-dimension links which were both positively and negatively correlated. These links can be utilized to determine which design features will increase or decrease the perception of another. For example, as the amount of padding increases, so does the perceived weight.

These results can be used to develop further qualitative and quantitative tests designed to gain a greater understanding of how each general dimension affects perceived comfort and aid in building a more detailed product design specification. The approach from this study could also be utilized for other pieces of sporting apparel and equipment, as well as within other industries.

This study supports the work of Roberts et al. [29] in demonstrating the effectiveness of combining a practical element within the interview process to stimulate more responses from participants, rather than merely relying on retrospective analysis of products. The benefit of utilizing a practical evaluation was highlighted by participants' regular comparison

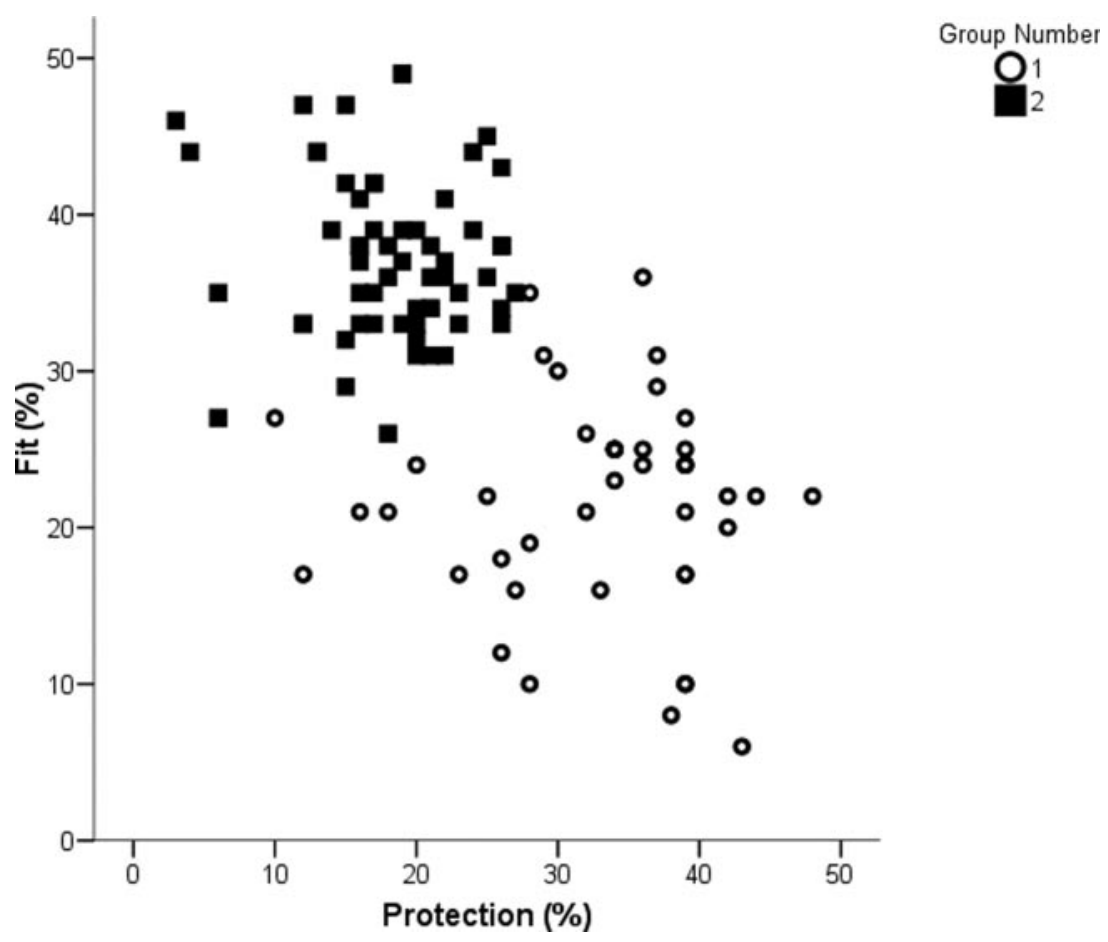

Fig. 5 Fit and protection weightings of the two clusters of participants identified within the cluster analysis 
between their own pads and the different pads used in the test.

'This pad was a lot heavier than my pad so it made me feel like I couldn't move as well.'

No previous comfort analysis of sporting equipment has identified specific comfort parameters as perceived by the user, the extent that each parameter contributes to overall comfort, or their interactions that determine the users' perceived comfort. This study suggests that a comprehensive model of this nature needs to be developed and utilized within the design process to help to maximize user comfort and performance, through incorporating the end user within the design process at an earlier stage.

\section{CONCLUSION}

This study used a combination of qualitative methods to determine and construct a representative comfort model for cricket leg guards, highlighting the contributory effects of different characteristics that need to be considered within the design process. Initially, an inductive analysis was performed on the data, identifying core dimensions which were validated through a second data collection utilizing a deductive analysis procedure. Further to this, interdimension links were identified through the data collection and portrayed within a structured relationship model. Six general dimensions, namely weight, thermal comfort, protection, fit, sensorial comfort and aesthetics emerged, which were related through 13 inter-dimension links. The final developmental stage of the comfort model was to assign weightings to each of these dimensions through the use of an online questionnaire and an AHP analysis procedure. These results identified that fit was the most important factor for comfort, followed by protection with aesthetics and sensorial comfort being the least important factors.

This study has focused on cricket leg guards but could easily be adapted for other sports and industries, which help to provide manufacturers with more detailed information allowing for comfort to be maximized and thereby increasing user satisfaction.

\section{ACKNOWLEDGEMENTS}

The authors would like to thank the Sports Technology Institute at Loughborough University for providing facilities and technical staff that enabled this study to be completed. Sincere appreciation is extended to the cricketers who donated their time and expertise within the testing.

\section{REFERENCES}

1 Peter, J. P. and Olsan, J. C. Consumer behaviour and marketing strategy, 2005 (McGraw-Hill, New York).

2 Barsky, J. and Nash, L. Evoking emotion: affective keys to hotel loyalty. Cornell Hotel Restaurant Adm. Q., 2002, 43, 39-46.

3 Vink, P. Comfort and design, 2005 (CRC Press, London).

4 Fox, E. L., Mathews, D. K., Kaufman, W. S., and Bowers, R. W. Effects of football equipment on thermal balance and energy cost during exercise. Res. Q., 1966, 37, 332-339.

5 Kirk, W. J. R. and Ibrahim, S. M. Fundamental relationship of fabric extensibility to anthropometric requirements and garment performance. Text. Res. J., 1966, 36(1), 37-47.

6 Cian, C., Koulmann, N., Barraud, P. A., Raphel, C., Jimenez, C., and Melin, B. Influence of variations in body hydration on cognitive function: effect of hyperhydration, heat stress, and exercise-induced dehydration. J. Psychophysiology, 2000, 14(1), 29-36.

7 Rock, K. M., Mikat, R. P., and Foster, C. The effects of gloves on grip strength and three point pinch. J. Hand Therapy, 2001, 14(4), 286-290.

8 Sawka, M. N., Montain, S. J., and Latzka, W. A. Hydration effects on thermoregulation and performance in the heat. Comp. Biochemistry Physiology Part A: Molecular Integrative Physiology, 2001, 12(8), 679-680.

9 Cardello, A. V., Winterhalter, C., and Schutz, H. G. Predicting the handle and comfort of military clothing fabrics from sensory and instrumental data: development and application of new psychophysical methods. Text. Res. J., 2003, 73(3), 221-237.

10 Civille, G. V. and Dus, C. A. Development of terminology to describe the handfeel properties of paper and fabrics. J. Sensory Stud., 1990, 5, 19-32.

11 Fourt, L. and Hollies, N. R. S. Clothing; comfort and function, 1970 (Marcel Dekker, New York).

12 Pontrelli, G. J. Partial analysis of comfort's gestalt. In Clothing comfort (Eds N. R. S. Hollies and R. F. Goldman), 1977, pp. 71-80 (Ann Arbor Science, Ann Arbor, Michigan).

13 Sontag, M. S. Comfort dimensions of actual and ideal insulative clothing for older woman. Clothing Text. Res. J., 1986, 4, 9-17.

14 Branson, D. H. and Sweeney, M. M. Clothing comfort conceptualization and measurement: toward a metatheory. In Critical linkages in textiles and clothing: theory, methods and practice. (Eds S. Kaiser and M. L. Damhorst), 1991, (Information Technology Association of America, Arlington, Virginia).

15 Akbar-Khanzadeh, F., Bisesi, M. S., and Rivas, R. D. Comfort of personal protective equipment. Appl. Ergonomics, 1995, 26(3), 195-198.

16 Fan, J. and Chen, Y. S. Measurement of clothing thermal insulation and moisture vapour resistance using a novel perspiring fabric thermal manikin. Measmt Sci. Technol., 2002, 13, 1115-1123.

17 Schutz, H. G., Cardello, A. V., and Winterhalter, C. Perceptions of fiber and fabric uses and the factors contributing to military clothing comfort and satisfaction. Text. Res. J., 2005, 75(3), 223-232. 
18 Mackie, H. W., Legg, S. J., Beadle, J., and Hedderley, D. Comparison of four different backpacks intended for school use. Appl. Ergonomics, 2003, 34(3), 257-264.

19 Li, Y. and Wang, Z. A. S. W. Clothing biosensory engineering, 2006 (Woodhead Publishing Limited, Cambridge).

20 Ulrich, K. and Eppinger, S. Product design and development, 1995 (McGraw-Hill, New York).

21 Alcántra, E., Artacho, M. A., González, J. C., and Garcia, A. C. Application of product semantics to footwear design. Part I - Identification of footwear semantic space applying differential semantics. Int. J. Ind. Ergonomics, 2005, 35, 713-725.

22 Van Lottum, C., Pearce, K., and Coleman, S. Features of Kansei engineering characterizing its use in two studies: men's everyday footwear and historic footwear. Qual. Reliability Engng, 2006, 22, 629-650.

23 Barrass, D. F., Roberts, J., Jones, R., Hague, R., and Dickens, P. The use of structured relationship modelling techniques as a tool to elicit customizable product features. Proc. IMechE, Part C: J. Mechanical Engineering Science, 2008, 222(2), 247-255. DOI: 10.1243/ 09544062JMES761.

24 Oliveira, J. C. Advances in consumer-oriented product design engineering of foods. Food Sci. Technol. Res., 2003, 9(4), 311-315.

25 Scanlan, T. K., Ravizza, K., and Stein, G. L. An in-depth study of former elite figure skaters: I. Introduction to the project. J. Sport Exercise Psychology, 1989, 11, 56-64.

26 Scanlan, T. K., Ravizza, K., and Stein, G. L. An in-depth study of former elite figure skaters: II. Sources of enjoyment. J. Sport Exercise Psychology, 1989, 11, 65-83.

27 Gould, D., Eklund, R. C., and Jackson, S. A. 1988 US Olympic wrestling excellence: 1. Mental preparation, precompetitive cognition, and affect. Sport Psychologist, 1992, 6, 358-382.

28 Gould, D., Eklund, R. C., and Jackson, S. A. 1988 US Olympic wrestling excellance: 2. Thoughts and affect occurring during competition. Sport Psychologist, 1992, 6, 383-402.

29 Roberts, J. R., Jones, R., Harwood, C. G., Mitchell, S. R., and Rothberg, S. J. Human perceptions of sports equipment under playing conditions. J. Sports Sci., 2001, 19(7), 485-497.

30 Jordan, P. W. Designing pleasurable products: an introduction to the new human factors, 2000 (Taylor \& Francis, London).

31 Oppermann, M. Triangulation - a methodological discussion. Int. J. Tourism Res., 2000, 2, 141-146.
32 Steenkamp, J. B. E. M. and Van Trijp, H. C. M. Attribute elicitation in marketing research: a comparison of three procedures. Marketing Lett., 1997, 8(2), 153165.

33 Patton, M. Q. Qualitative research and evaluation method, 2001 (Sage Publications, London).

34 Ashdown, S. P. and DeLong, M. Perception testing of apparel ease variation. Appl. Ergonomics, 1995, 26(1), 47-54.

35 Erlandson, D. A., Harris, E. L., Skipper, B. L., and Allen, S. D. Doing naturalistic inquiry: a guide to methods, 1993 (Sage Publications, Thousand Oaks, California).

36 Takemura, Y., Sakurai, Y., Yokoya, S., Otaki, J., Matsuoka, T., Ban, N., Hirata, I., Miki, T., and Tsuda, T. Open-ended questions: are they really beneficial for gathering medical information from patients? Tohoku J. Expl Medicine, 2005, 206(2), 151-154.

37 Thomas, D. R. A general inductive approach for analyzing qualitative evaluation data. Am. J. Evaluation, 2006, 27(2), 237-246.

38 Corbin, J. and Strauss, A. L. Grounded theory research: procedures, canons, and evaluative criteria. Qual. Sociology, 1990, 13(19), 3-19.

39 Saaty, T. L. The analytical hierarchy process: planning, priority setting, resource allocation, 1980 (McGraw-Hill, New York).

40 Efron, B. Bootstrap methods: another look at the jackknife. Ann. Statist., 1979, 7, 1-26.

41 Efron, B. and Tibshirani, R. J. An introduction to the bootstrap, 1993 (Chapman \& Hall, New York).

\section{APPENDIX}

\section{Notation}

$a_{i j} \quad$ quantified judgement of a pair of elements

CI consistency index

CR consistency ratio

$C_{i} \quad$ element

$n$ number of general dimensions

RI random consistency

w weighting 